\title{
A COMPREENSÃO DE EDUCAÇÃO AMBIENTAL EM UMA ESCOLA PÚBLICA DE ENSINO MÉDIO NO MUNICÍPIO DE SERRA (ES)
}

Silas Alves de Souza ${ }^{1}$

Jose Geraldo Ferreira da Silva²

Resumo: Os crescentes casos de degradação do meio ambiente conduziram a esta pesquisa, pois para existir uma sociedade mais conscientizada é preciso inserir, permanentemente, o conceito de Educação Ambiental no ambiente escolar. Essa é uma das principais alternativas para mudar essa situação, ou seja, mostrar para os jovens estudantes a importância de preservar o meio ambiente, pois são eles que, por meio da construção de conhecimentos acerca do meio ambiente, podem alcançar um futuro com menos poluição e destruição dos recursos naturais. Este estudo pretendeu mostrar o conceito de Educação Ambiental, primeiramente com um sucinto levantamento histórico acerca desse tema e, posteriormente, apresentando os resultados da pesquisa sobre o que os alunos da Escola Estadual de Ensino Fundamental e Médio Rômulo Castello sabem sobre o conceito de Educação Ambiental. Com base nas respostas obtidas, foram propostas alternativas para trabalhar essas questões de modo a sensibilizar todo o ambiente escolar e, assim, promover uma escola mais humanizada com as questões ambientais.

Palavras-chave: Educação Ambiental; Meio Ambiente; Preservação.

\footnotetext{
${ }^{1}$ Faculdade Vale do Cricaré. E-mail: silas_217@hotmail.com

${ }^{2}$ Faculdade Vale do Cricaré e Instituto Capixaba de Pesquisa Agropecuária e Extensão Rural.. E-mail: jgeraldo@incaper.es.gov.br
} 


\title{
Introdução
}

Embora os seres humanos tenham consciência de que são dependentes e de que precisam da natureza, ainda sim não a tratam como deveria, visto que ao longo do desenvolvimento da vida e do avanço da tecnologia o mais impactado por isso é o meio ambiente. Isso porque onde hoje há grandes cidades, bairros, lavouras ou até fazendas, certamente, um dia foi uma grande floresta. Devido a isso, a consciência para proteger a natureza surge dos problemas causados pela degradação do meio ambiente, sendo necessárias ações para preservá-la. No Brasil, a ideia da proteção do meio ambiente surgiu em 1808 com a criação do Jardim Botânico no Rio de Janeiro e, em 1850, com a Lei no 601 de Dom Pedro II proibindo a exploração florestal nas terras descobertas. No entanto, essa lei foi ignorada e o desmatamento continuou para implantação da monocultura de café.

Diante dessa realidade, estimular a conscientização para preservar o meio ambiente deve começar cedo e ser permanente. A Educação Ambiental tem o papel fundamental para que isso ocorra, segundo o MMA, a Educação Ambiental:

\begin{abstract}
São processos por meio dos quais o indivíduo e a coletividade constroem valores sociais, conhecimentos, habilidades, atitudes e competências voltadas para a conservação do meio ambiente, bem de uso comum do povo, essencial à sadia qualidade de vida e sua sustentabilidade (PNEA 99).
\end{abstract}

Nas escolas, a Educação Ambiental deve ser trabalhada como tema transversal nas diretrizes curriculares e, nesse sentido, esta pesquisa visa verificar como esse tema é trabalhado nas salas de aula. Para desenvolvê-la, foi selecionada uma escola estadual pública localizada no município de Serra- ES.

O papel da escola é essencial para que as crianças cresçam conscientes e aprendam a amar o meio ambiente, a escola pode colaborar muito e deve mostrar na prática por que é importante preservar a natureza, pois muitos jovens não conhecem os benefícios proporcionados pela natureza.

\section{Aspectos históricos e culturais da Educação Ambiental}

Segundo o caderno intitulado SECAD-MEC 2007, o termo Educação Ambiental surgiu primeiramente em 1948, no Encontro da União Internacional para a Conservação da Natureza em Paris, mas foi somente em 1972, a partir da Conferência de Estocolmo, que os rumos da Educação Ambiental foram traçados. Em 1975 foi lançado o Programa Internacional de Educação Ambiental que definiu estratégias e orientações para o futuro.

A cultura do desmatamento por muito tempo vem assombrando as delas. Há, inclusive, diversos casos de extração clandestina de madeiras que Revbea, São Paulo, V. 14, № 2: 177-188, 2019. 
acabam com a vida no território explorado. Há previsão de penas também na lei $n^{\circ}$ 9.605/98 para quem cortar árvores em floresta considerada de preservação permanente, sem permissão da autoridade competente, mesmo que a floresta esteja em formação.

Embora haja problemas consideráveis referentes ao meio ambiente, nos últimos anos vem crescendo a conscientização de questões ambientais, o termo sustentabilidade foi incorporado por várias empresas e pessoas, entendendo-se sustentabilidade como maneiras de explorar os recursos naturais de forma a não agredir o meio ambiente.

\section{Educação Ambiental nas escolas}

A Educação Ambiental é o caminho para conscientizar a população de modo a formar cidadãos mais conscientes e preocupados com as questões ambientais. Objetiva também formar um ser humano mais harmonioso e capaz de refletir sobre os problemas enfrentados pelo meio ambiente, além de pensar em estratégias e novas formas de agir para que eles não se repitam.

De acordo com o art. 10 da Política Nacional de Educação Ambiental, a Educação Ambiental deve ser desenvolvida como uma prática educativa integrada, contínua e permanente em todos os níveis e modalidades do ensino formal. Amaro (2015) destaca que:

O tema meio ambiente permeia a sociedade com questões e reflexões que demandam atenção e urgência, levantando a importante relação existente entre a ciência, a tecnologia, a sociedade e o ambiente no qual estamos inseridos. Pode-se destacar o fato de que o desenvolvimento social, econômico e tecnológico do mundo moderno vem exigindo, cada vez mais, a formação de cidadãos mais conscientes, reflexivos e críticos frente à realidade que os cerca e em um contexto marcado pela degradação do meio ambiente (AMARO, 2015, p. 16).

Desse modo, a escola tem o papel de formar cidadãos mais conscientes em questões direcionadas ao meio ambiente, pois ela é um ambiente propício para que as crianças cresçam sabendo que devem respeitar e preservar a natureza. É preciso preparar esses jovens e ensiná-los que é fundamental preservar e ter atitudes sustentáveis.

\section{Materiais e métodos}

Após a escolha do tema Educação Ambiental nas escolas, a pesquisa foi aplicada na Escola Estadual de Ensino Fundamental e Médio Rômulo Castello, localizada no município de Serra-ES. O local foi escolhido por oferecer a $1^{\underline{a}}$

revista brasileira educação ambiental 
série do Ensino Médio, pois os estudantes dessa série recentemente passaram pela transição do Ensino Fundamental para o Ensino Médio. Isso possibilitou verificar como o tema Educação Ambiental é trabalhado no Ensino Médio e como os alunos que terminam o Ensino Fundamental estão assimilando esse conceito.

A amostra compreendeu 40 alunos matriculados na $1^{\text {a }}$ série do Ensino Médio e oito professores dessa escola. Utilizou-se como critério único de inclusão estar matriculado na $1^{\text {a }}$ série do Ensino Médio, no caso de alunos, ou ser professor da Escola Estadual de Ensino Fundamental e Médio Rômulo Castello.

Para a coleta de dados, foi elaborado um questionário com 11 questões abertas e fechadas para os alunos e, para os professores, um questionário com 8 questões também abertas e fechadas. Utilizou-se para aplica-lo a plataforma fornecida pelo Google, o Google formulários.

O questionário destinado aos alunos foi enviado por link para os grupos de Whatsapp de cada turma, obtendo-se, assim, um total de 40 respostas. $O$ questionário para os professores foi enviado por link para o grupo de Whatsapp dos professores da escola, obtendo-se, assim, oito respostas.

\section{Resultado da pesquisa}

A pesquisa envolveu professores e alunos, e os participantes foram informados de que não precisariam se identificar de modo a preservar suas identidades. Contudo, apesar do pedido para responder os questionários, não houve uma aceitação por parte dos professores, tivemos oito respostas. Por parte dos alunos obteve-se um número significativo de respostas, com 40 questionários respondidos. Com os dados coletados por meio do questionário foi possível descrever como os professores têm trabalhado a Educação Ambiental em suas aulas, bem como foi possível analisar como esse tema é assimilado pelos estudantes.

\section{Professores}

Os professores que participaram da pesquisa têm idades entre 23 e 65 anos, $37,5 \%$ possuem ensino superior, $37,5 \%$ possuem pós-graduação, $12,5 \%$ mestrado e $12,5 \%$ doutorado em andamento.

A primeira pergunta pretendeu verificar o que entendiam sobre Educação Ambiental, cujo resultado encontra-se na Tabela 1 a seguir. 
Tabela 1: O que você entende por Educação Ambiental?

Instrumento didático destinado a questionar práticas arraigadas no comportamento cotidiano que prejudicam o ambiente vivenciado local e globalmente, bem como envolver o público em práticas que garantam o equilíbrio entre a sociedade e a natureza.

Trabalho pedagógico que busca a conscientização de alunos sobre as possibilidades de usos e as limitações dos recursos naturais renováveis e não renováveis, colocando o homem como parte integrante da natureza, que a afeta e é afetado por ela.

Entender a importância da natureza para a sociedade e respeitar o meio ambiente através de condutas corretas.

Ser consciente de que o futuro das nações depende de práticas sustentáveis efetivas, por parte de todos.

Preocupação, cuidado e respeito ao meio ambiente.

Ensinar sobre como utilizar os meios naturais com consciência

Ensino voltado para a sensibilização dos envolvidos, à importância de um relacionamento equilibrado com as diferentes paisagens.

Convivência pacífica e de respeito com o meio ambiente.

Fonte: Autoria própria.

Assim, a Educação Ambiental deve ser trabalhada como tema transversal em todas as etapas do ensino. Segundo Sato (2008), a Educação Ambiental no ensino formal tem enfrentado inúmeros desafios, entre os quais destaca-se o de como fazer a inserção da Educação Ambiental na prática educativa em sua condição de transversalidade.

Com relação à segunda questão, buscou-se compreender se o professor trabalha com o tema na disciplina que ministra. O resultado está expresso na Figura 1 a seguir.

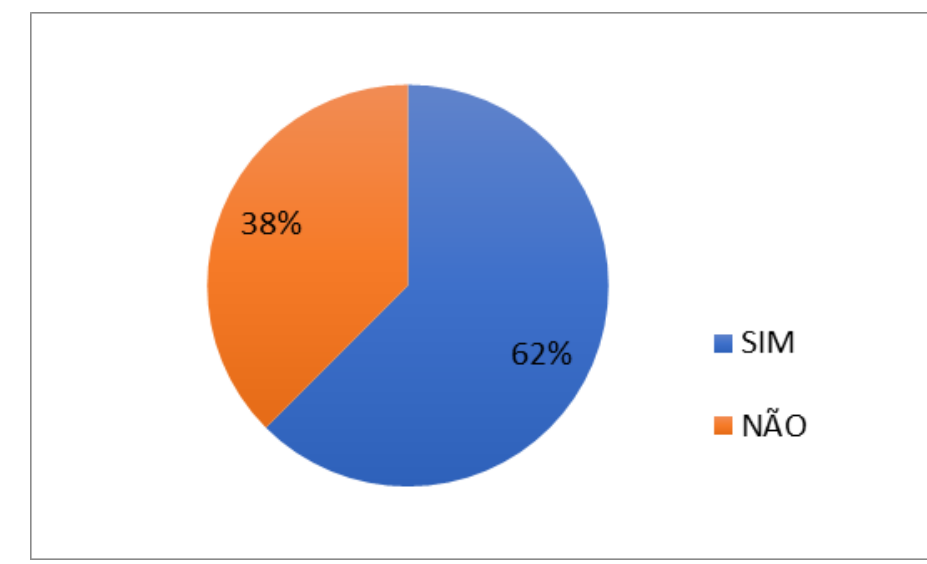

Figura 1: Respostas dos professores quando perguntados se trabalham o tema Educação Ambiental na disciplina que ministra. Fonte: Autoria própria

Já na Tabela 2 é possível observar como o professor tem trabalhado esse tema em suas aulas; aqueles que trabalham esse tema têm usado técnicas que estão mostrando ao aluno como é importante falar em proteção 
ao meio ambiente. Além disso, mostra a eles como descuidos, como o simples fato de destinar o lixo em locais inadequados, pode prejudicar um ambiente, um bairro, uma cidade.

Tabela 2: Como você trabalha esse tema?

Desde a organização da sala de aula, durante o período letivo, como também em debates, aulas de campo e visitas técnicas e investigativas.

Abordando o porquê de enchentes, limpeza da própria escola e lugares públicos.

Exposição e debates.

A partir de leitura de textos, charges e em relação à literatura. Discussão, debates e exercícios sobre conservação.

Mesclando os conteúdos básicos com a importância de respeitar os meios em que estamos inseridos.

Fonte: Autoria própria.

Quando questionados sobre a importância de se trabalhar o tema Educação Ambiental, todos responderam sim a essa pergunta, mesmo os professores que não trabalham esse tema entendem a importância em ensinar o aluno sobre Educação Ambiental.

$\mathrm{Na}$ Tabela 3, os professores responderam porque consideram importante trabalhar o tema Educação Ambiental. Pode-se afirmar pelas respostas que os docentes consideram importante trabalhar o tema para que a sociedade seja composta por cidadãos mais conscientes acerca das questões ambientais. Assim, ao trabalhar esse tema transversal, a escola formará cidadãos mais conscientes.

Tabela 3: Por que considera importante trabalhar o tema Educação Ambiental?

Pela urgência de serem revistos paradigmas intrínsecos da cultura consumista, pela consciência holística e pela superação do individualismo.

Porque compreender o funcionamento e limitação do meio ambiente é fundamental para o crescimento sustentável, o uso consciente de recursos naturais e a preservação da natureza.

\section{Conscientização para uma sociedade}

Despertar a consciência dos discentes.

Dada a realidade da degradação ambiental e a importância da formação de sujeitos críticos e conscientes da realidade.

Pois é necessário que vivamos em harmonia com o meio.

É um importante tema transversal para ser trabalhado em todas as disciplinas contribuindo para a formação integral do educando.

Para a preservação do meio ambiente.

Fonte: Autoria própria.

É possível observar na Figura 2 que a metade dos professores que participaram da pesquisa considera que a Educação Ambiental deve ser trabalhada como disciplina. A disciplina Educação Ambiental seria uma forma 
de abordar as questões ambientais durante todo o ano, de forma a estimular os discentes a aprender a viver de maneira mais sustentável.

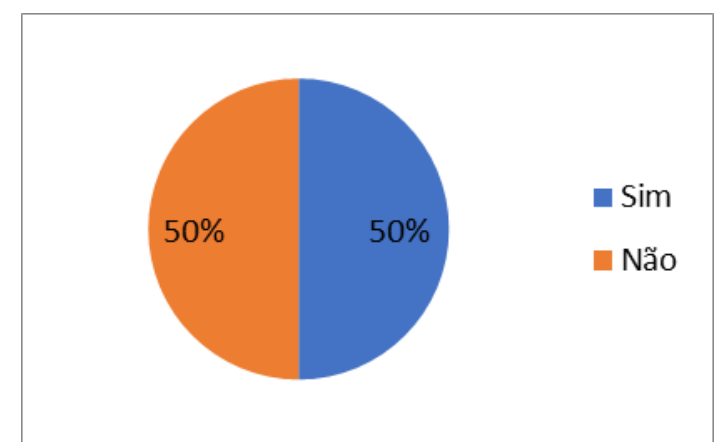

Figura 2: Considera que a Educação Ambiental deveria ser trabalhada como disciplina? Fonte: Autoria própria

\section{Alunos}

A pesquisa feita com os alunos da $1^{\text {a }}$ série do Ensino Médio identificou que $23 \%$ têm 15 anos, $40 \%$ têm 16 anos, $23 \% 17$ anos e $15 \%$ têm 18 anos. As figuras 3 e 4 mostram que a maioria dos alunos sabe e ouve falar sobre Educação Ambiental. Muitos alunos da 1aㅡ série do Ensino Médio já ouviram e sabem o que é Educação Ambiental, são estudantes que já passaram da etapa do Ensino Fundamental e muitos estudaram o tema nessa etapa, e uma vez que a Educação Ambiental deve ser trabalhada em todas as etapas de formação do cidadão.

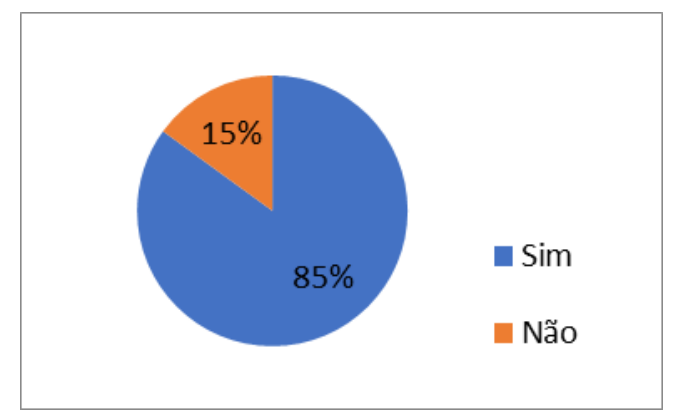

Figura 3: Você sabe o que é Educação Ambiental? Fonte: Autoria própria

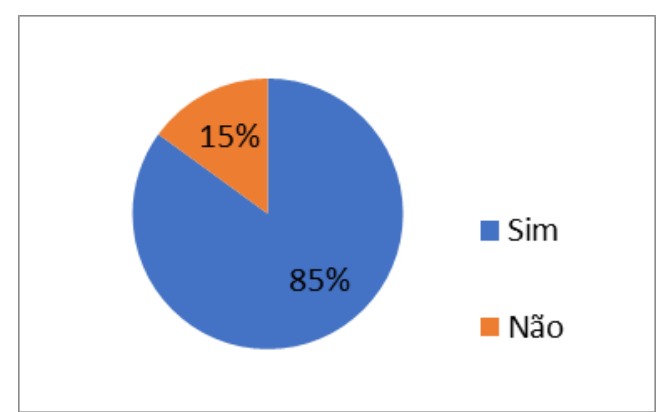

Figura 4: Já ouviu falar sobre Educação Ambiental? Fonte: Autoria própria.

Ao perguntar onde eles ouviram falar sobre Educação Ambiental, as respostas foram as seguintes: $32,5 \%$ responderam na escola, $22,5 \%$, televisão, $7,5 \%$, jornal, $20 \%$, palestras e $17,5 \%$, internet. Pode-se observar que mais da metade respondeu na escola ou palestras, mostrando que a escola é o principal meio que há para tornar esses jovens mais conscientes acerca das questões ambientais. 


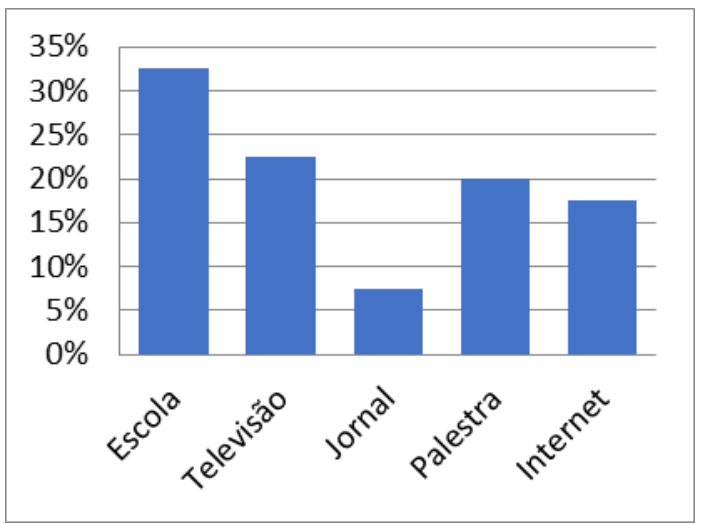

Figura 5: Resultado da pergunta onde ouviram falar sobre Educação Ambiental? Fonte: Autoria própria

As Figuras 6 e 7 mostram os resultados obtidos sobre o questionamento feito aos discentes se o tema educação é trabalhado na escola e se consideram importante trabalhar o tema Educação Ambiental. A maioria das respostas dada pelos alunos foi sim. Os jovens entendem que ao estudar questões ambientais um dos propósitos é transformar, melhorar o meio ambiente em que vivemos, e a escola tem responsabilidade em sua função de formadora de cidadãos pensantes e proativos.

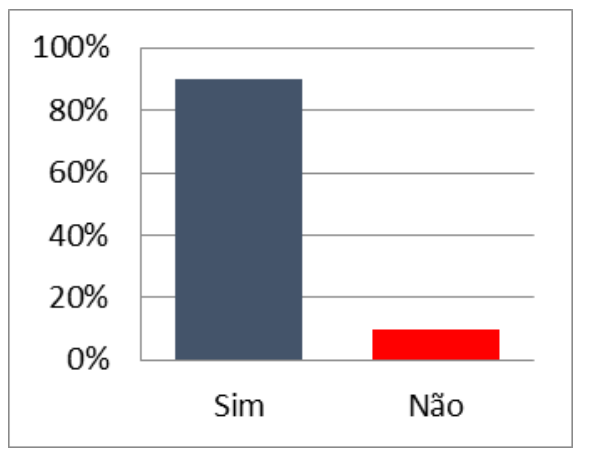

Figura 6: Na escola é trabalhado o tema Educação Ambiental?

Fonte: Autoria própria.

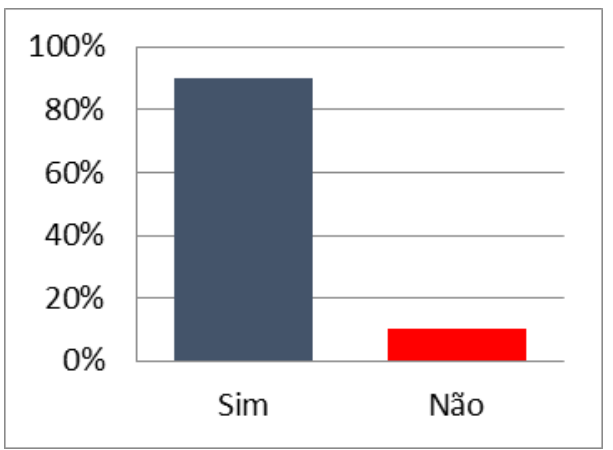

Figura 7: Você acha importante estudar o tema Educação Ambiental em sala de aula?

Fonte: Autoria própria.

Já a Figura 8 contém o resultado da pergunta referente a jogar ou não lixo na rua. Assim, ao serem questionados se jogam lixo na rua, $10 \%$ dos alunos disseram que jogam. Desse modo, a maioria dos alunos tem consciência de que não se deve jogar lixo na rua, inclusive, compreendem que jogar lixo na rua pode causar grandes problemas para os moradores, principalmente na época das chuvas, visto que podem ocorrer alagamentos, além de poluir rios. 


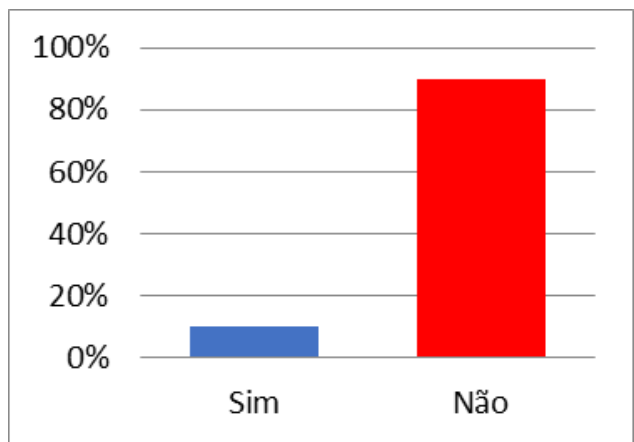

Figura 8: Você joga lixo na rua?

Fonte: Autoria própria.

Os alunos também foram questionados sobre a importância de preservar o meio ambiente, cuja resposta unânime foi sim, pois consideram importante preservá-lo. Os alunos têm essa consciência de preservar a natureza, mas é preciso intensificar ações para que eles pratiquem atividades mais sustentáveis em sua vida adulta.

Já a Figura 9 representa o resultado da pergunta: $O$ desmatamento prejudica o meio ambiente? De acordo com o resultado, $10 \%$ dos alunos desconhecem que o desmatamento prejudica o meio ambiente e, quando questionados como o desmatamento pode prejudicar o meio ambiente, a maioria não deu uma resposta aceitável. $27,5 \%$ não responderam como o desmatamento pode prejudicar o meio ambiente, os que responderam não souberam dizer de forma clara como isso ocorre. Desse modo, isso mostra que nem sempre eles sabem o que pode ocorrer quando acontece alguma destruição ambiental.

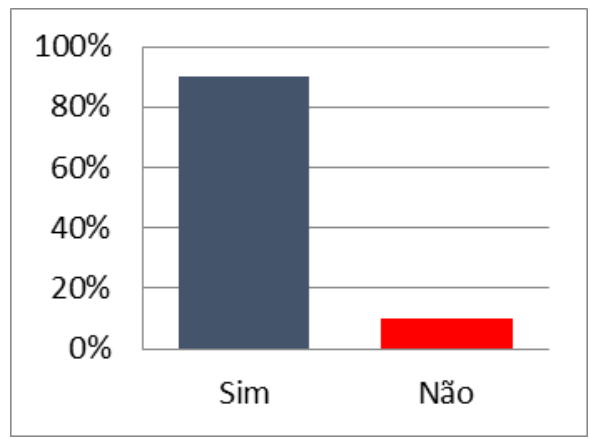

Figura 9: O desmatamento prejudica o meio ambiente? Fonte: Autoria própria.

Ainda em relação ao prejuízo ao meio ambiente, na Tabela 4 estão as respostas dos alunos sobre como o desmatamento pode prejudicar o meio ambiente. Entre os participantes, $72,5 \%$ deles responderam a essa pergunta, mas muitas respostas não foram claras. No entanto, os alunos precisam entender que é fundamental saber como se comportar em relação a atitudes 
que prejudicam o meio ambiente e compreender como essas atitudes influenciam e interferem na natureza.

Tabela 4: Como o desmatamento pode prejudicar o meio ambiente?

Poluindo os rios e o aumento de gases tóxicos.

Das piores formas possíveis.

Com a falta de árvores ocorre a extinção de alguns animais.

Falta de oxigênio e dificultando a infiltração de água no solo para o lençol freático

Pode causa um desequilíbrio natural no nosso planeta.

Seca

Basicamente, diminuição da evapotranspiracao, reduzindo a precipitação.

Por conta das árvores que são cortadas ficamos cada vez mais com menos oxigênio.

Distribuição do habitat dos animais.

Colaborando com a erosão do solo.

Com a poluição do ar.

Devido ao desmatamento, a vida no meio ambiente pode ser prejudicada devido a isso.

Menos ar limpo, mais pessoas doentes, animais entrando em extinção e morrendo...

Perda de biodiversidade da fauna e flora nativas, comprometimento da vazão dos rios etc...

Provocando mudanças na atmosfera, prejudicando a alimentação de várias espécies de animais e, até mesmo, a extinção de várias espécies de plantas.

Deixando animais sem lazer prejudicando o ar da atmosfera.

Tirando o Lar de muitos animais que acabam causando acidentes etc...

Comprometendo a natureza.

Pelo fato de tirar as raízes daquele, impedindo que o rio transborde, enfraquece as nascentes.

O desmatamento prejudica o meio ambiente de várias formas e isso não prejudica só o meio ambiente, mas sim a todos que nele vive.

Prejudica a atmosfera, prejudica o meio ambiente.

Acabando com as nascentes e destruindo toda erva que não tem.

Causando grandes impactos ambientais e muitos problemas na atmosfera, e aumentando o efeito estufa.

NAO FAÇO A MENOR IDEIA.

Trazendo poluição.

Acaba com as árvores, o meio ambiente etc.

Estraga.

Todos os sentidos.

As pessoas de hoje em dia só sabem tirar da natureza, e não colocam de volta..

Fonte: Autoria própria.

Os alunos também foram questionados, conforme a tabela 5, acerca do que entendem como Educação Ambiental. No entanto, apenas 47,5\% dos participantes responderam, o que representa um número pequeno, muito embora a maioria já tenha ouvido falar de Educação Ambiental. Além disso, as respostas não foram claras. Isso mostra que a Educação Ambiental precisa ser trabalhada nas escolas de maneira a transformar os alunos em seres mais compreensivos em relação à natureza, e esse conteúdo deve ser mais significativo para a vida deles.

Revbea, São Paulo, V. 14, № 2: 177-188, 2019. 
Tabela 5: O que você entende sobre Educação Ambiental?

Cuidar melhor da natureza para temos um futuro melhor.

Preservação dos meios básicos para a sobrevivência.

Pouca coisa, não é estudado na nossa escola, não me interessa muito esse tipo de estudo.

Eu entendo que ela é usada para preservar o meio ambiente

Como uma forma de ensinar as pessoas que afetando o meio ambiente, automaticamente, estaremos afetando a nós mesmos.

Entendo sobre o que se passa ali na natureza, os danos que podem ser causados etc.

É ensinar e falar como é importante manter o ambiente limpo saudável, bem cuidado ...

A Educação Ambiental me leva a preservar o meio ambiente, não prejudicando a fauna e a flora, utilizá-lo de forma sustentável.

E a forma de colaborar para que o meio ambiente seja mais limpo e preservado. Um modo também de manter várias espécies de animais e plantas vivas e bem cuidadas!

Conserva o meio ambiente.

E saber o que é ambiente, como preservar, o que fazer para que ele não acabe.

Acho que é um processo de educação com as pessoas a se preocuparem com o meio ambiente

Eu entendo que todos nos temos que cuidar do meio ambiente para que as próximas gerações do futuro possam ter os mesmos direitos que o nosso, porque o ambiente não e só nosso, mas sim das furas gerações também.

Ensinar a saber que não devemos poluir o meio ambiente.

É modo de ensinar as pessoas de como tratar o meio de ambiente de forma correta e eficaz, e ensinar as pessoas que a nossa única fonte de vida é meio ambiente, pois se não houver um bom meio ambiente, não há vida.

E um processo por meio do qual o indivíduo constrói valores sociais, conhecimentos, habilidades, atitudes e competências voltadas para a conservação do meio ambiente.

Ensinar a manter a natureza.

Cuida do nosso planeta.

Educação Ambiental vem de ensinar a preservação do meio ambiente. Acho que é necessário sim aprender sobre Educação Ambiental desde criança, em creches, e que as crianças das escolas públicas tenham mais tempo nessa disciplina acho que seria mesmo até questão de obrigação!

Fonte: Autoria própria.

\section{Considerações finais}

Durante a pesquisa surgiram dificuldades referentes ao retorno do questionário enviado aos professores, pois um número pequeno de professores participou da pesquisa, o que caracteriza um desinteresse em participar de pesquisas envolvendo o tema Educação Ambiental. Contudo, convém ressaltar que a Educação Ambiental deve ser trabalhada na escola para formar e preparar cidadãos mais conscientes no que se refere às questões ambientais e ao meio ambiente.

A Educação Ambiental é uma dimensão da educação, é atividade intencional da prática social, que deve imprimir ao desenvolvimento individual um caráter social em sua relação com a natureza e com os outros seres humanos, visando potencializar essa atividade humana com a finalidade de tornála plena de prática social e de ética ambiental. (Diretrizes Curriculares Nacionais para a Educação Ambiental, art. $2^{\circ}$ ) 
Nessa perspectiva, as atividades desenvolvidas na escola devem ser permanentes. O objetivo deve ser capacitar o aluno de forma que ele consiga entender o quanto é importante pensar e agir de forma diferente, bem como formar cidadãos mais conscientes em relação à preservação e à conservação, que pensem em alternativas de sustentabilidades, sendo a escola o espaço para formar esse cidadão. Mello (2007) afirma que é preciso repensar os próprios objetivos de projetos e práticas pedagógicas. É muito comum afirmar que o objetivo da Educação Ambiental é conscientizar alunos e comunidades, mas é preciso fazer de forma mais significativa, objetiva e direcionada.

As visitas em parques, lixões, cooperativas, estações de tratamento de água, estações de tratamento de esgoto, áreas de conservação ambiental etc. são algumas alternativas para a escola mostrar aos alunos a necessidade de ser mais consciente com 0 ambiente em que vive. É preciso também questionar o aluno o porquê de enchentes, da crise hídrica, do desmatamento, da extinção de espécies, ou seja, são temas importantes para se trabalhar na escola. Além disso, é preciso mostrar alternativas para o aluno viver de forma sustentável.

\section{Referências}

ANDRADE, D.F. Implementação da Educação Ambiental em escolas: uma reflexão. Revista Eletrônica do Mestrado em Educação Ambiental, v. 4. out/nov/dez 2000.

AMARO, R. E. Matemática e Práticas de Educação Ambiental: Uma Modelagem no Exercício de uma Sequência Didática. Dissertação, Mestrado profissional Ciências, Tecnologia e Educação. Faculdade Vale do Cricaré, 2015.

BRASIL. Lei Federal 9.795, de 27 de abril de 1999. Política Nacional de Educação Ambiental.

CARVALHO, I.C.M. Educação Ambiental: a formação do sujeito ecológico. 2.ed. São Paulo: Cortez, 2006.

CAMPIANI, M.C. Os temas transversais na educação. S.Paulo: Códex, 2001.

DIAS, G.F. Educação Ambiental: princípios e práticas. São Paulo: Gaia, 2003.

GUIMARÃES, M. A dimensão ambiental na educação. 5.ed. Campinas: Papirus, 1995.

HENRIQUES, R., TRAJBER R. Educação Ambiental: aprendizes de sustentabilidade. Ministério da Educação, Secretaria de Educação Continuada, Alfabetização e Diversidade (Secad/MEC). 2007. 109 p.

MELLO, S.S.; TRAJBER, R. Vamos cuidar do Brasil: conceitos e práticas em Educação Ambiental na escola. Ministério da Educação: Ministério do Meio Ambiente: UNESCO, 2007. 248 p.

REIGOTA, M. O que é Educação Ambiental. São Paulo: Brasiliense, 2006.

SILVA, M. Encontros e Caminhos: Formação de Educadoras(es) Ambientais e Coletivos Educadores. Brasília, Ministério do Meio Ambiente, 2005. 